\title{
Factors affecting the use of herbal products in patients with Irritable Bowel Syndrome and their results: case-control study
}

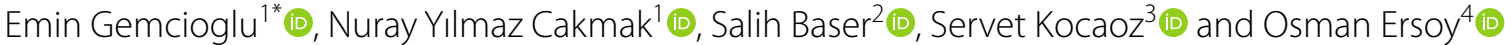

\begin{abstract}
Background: Irritable bowel syndrome (IBS) is a functional bowel disease that is characterized by abdominal pain, discomfort, and changes in the frequency and form of stool without any organic pathology. In this study, the factors that affect the herbal treatment choices of IBS patients and their results were investigated.
\end{abstract}

Methods: Included in the study were 248 IBS patients who were over the age of 18. A questionnaire that comprised 25 questions was applied to the participants. Survey questions were asked to the participants regarding their age, place of birth, gender, educational status, demographic details, social standing, socioeconomic status and job, place of residence, and marital status. In addition, The participants were asked about which IBS symptoms they had, from whom they had received the recommendation for use of herbal products, whether the media had an effect on their selection of herbal products, and whether they had benefited from herbal products.

Results: It was observed that $41.1 \%$ of the patients with IBS who participated in the study used herbal medicine, $9.8 \%$ of whom used them regularly. It was found that the IBS patients participating in the study made their decision to use herbal products mostly based on the recommendations that they were given by acquaintances (57\%) and the media (34\%). When the patients were evaluated according to their gender, IBS was found to be more common in unemployed women who had a low level of education, while it was more common in working men $(p=0.015$, $P<0.001$, respectively). The IBS patients who were single used more herbal products that those who were married $(P=0.036)$. While the use of herbal herbs and oils was predominant in patients whose recommendation content comprised the media/internet and acquaintances, the herbal treatment content recommended by healthcare professionals consisted of traditional treatments and mixtures $(P=0.012)$. It was determined that a higher percentage of those who used herbal treatments lived in city centers when compared to those who did not $(P<0.001)$. In addition, it was determined that patients with constipation used herbal products more than those without $(P<0.001)$. Among the IBS patients, those who had diarrhea and those who were receiving medical treatment preferred to use significantly less herbal products ( $P=0.007$ and $P=0.041$, respectively). It was found that the patients who visited the Gastroenterology Outpatient Clinic mostly used herbal therapy, while those who visited a family doctor used herbal therapy the least $(P=0.029$ and $P<0.001$, respectively).

Conclusion: The IBS patients revealed whose recommendations they followed when purchasing herbal products, which of the products they preferred, and how useful/beneficial they felt that these products were. In this regard, the

\footnotetext{
*Correspondence: egemcioglu@gmail.com

1 Department of Internal Medicine, Ankara City Hospital, Ankara 06100,

Turkey

Full list of author information is available at the end of the article
} original author(s) and the source, provide a link to the Creative Commons licence, and indicate if changes were made. The images or other third party material in this article are included in the article's Creative Commons licence, unless indicated otherwise in a credit line to the material. If material is not included in the article's Creative Commons licence and your intended use is not permitted by statutory regulation or exceeds the permitted use, you will need to obtain permission directly from the copyright holder. To view a copy of this licence, visit http://creativecommons.org/licenses/by/4.0/. The Creative Commons Public Domain Dedication waiver (http://creativeco mmons.org/publicdomain/zero/1.0/) applies to the data made available in this article, unless otherwise stated in a credit line to the data. 
addition of training curricula related to herbal treatment for professional healthcare workers will further raise awareness on this topic.

Keywords: Irritable bowel syndrome, Herbal therapy, Audio-visual media

\section{Introduction}

Irritable bowel syndrome (IBS) is a functional bowel disease that is characterized by abdominal pain, discomfort, and changes in the frequency and form of stool without any organic pathology. IBS is the most common gastrointestinal system disease in patients who have visited internal and surgical outpatient clinics [1,2]. Its prevalence is increasing among individuals between the ages of 30 and 50. The disease is twice as common in women than in men worldwide, while this rate is 3 times more in Turkey $[3,4]$. High socioeconomic status and modern living conditions have been identified as risks for IBS development [5]. The chronic nature of IBS and the lack of an effective treatment cause a loss of workforce and worsening of the quality of life of patients [6]. IBS physiopathology includes genetic factors, intestinal microbiota, impaired immune system regulation, changes in intestinal permeability, and bowel-brain interaction [7]. Rome IV criteria are used in the diagnosis of IBS [8]. The main goal of treatment is to relieve symptoms. Patients frequently use alternative and complementary treatments due to the chronic nature of the symptoms, inadequate treatment response, and medication side effects in IBS [9]. Complementary and alternative treatments for IBS include hypnosis, acupuncture, cognitive behavioral therapy, yoga, and herbal medicine. Herbal medicine has a therapeutic effect as well as side effects in IBS $[9,10]$. Herbal products are usually used uncontrolled and without consulting a doctor or determining the correct dosage. A previous study found that the source of information of patients taking herbal therapy comprised other patients who had the same complaints, the media, the internet, their friends and relatives, spice merchants, and herbalists [11]. In this study, the factors that affect the herbal treatment choices of IBS patients and their results were investigated.

\section{Materials and methods}

In this study, patients who applied to the Internal Medicine and Gastroenterology Outpatient Clinic of a tertiary referral hospital, between January and April 2018, were evaluated. Among these patients, those whose clinical situations were in line with the ROME IV criteria were included in the study [8]. Those with malignancy and inflammatory bowel disease, who were pregnant, or had any alarm symptoms (recent onset and rapid exacerbation of complaints, onset of symptoms after the age of 50 , weight loss, fever, anemia, bloody defecation, symptoms awakening from sleep at night, family history of gastrointestinal cancer, antibiotics use, and travel history to countries with risk of infection) were excluded from the study. A questionnaire was applied to the patients who were accepted for participation in the study (Appendix).

Before the questionnaire was administered, the patients were informed about the aim of the study, verbal consent was obtained, and it was stated that they could withdraw from the study at any stage. The questionnaire included questions about the sociodemographic characteristics of the participants, IBS, and herbal therapy.

\section{Statistical analysis}

Statistical analysis of the data was performed using IBM SPSS Statistics 25.0 (IBM Corp., Armonk, NY, USA). The compliance of continuous numerical variables to normal distribution was tested using the Kolmogorov-Smirnov test. Among the descriptive statistics, the continuous numerical variables were presented as the mean \pm standard deviation or median [minimum (min) - maximum $(\max )]$, while the categorical variables were presented as the frequency and percentage. While the difference between the groups in terms of the mean was evaluated using the student $t$ test, the difference in terms of the median was evaluated using the Mann-Whitney $U$ test. The categorical variables were analyzed using the Pearson chi square test. Unless otherwise stated, $P<0.05$ was considered as statistically significant.

\section{Results}

The number of patients included in the study was 248 , and of these, 139 were women (56\%) and 109 (44\%) were men. The mean age of the patients was $43.6 \pm 13.5$ years; the mean age of the women was $44.5 \pm 13.0$ years, while the mean age of the men was $42.4 \pm 14$ years. Only $41.1 \%$ of the patients were receiving herbal treatment, $9.8 \%$ of whom were using it regularly. Of the IBS patients, $46 \%$ were primary and secondary school graduates, 23.4\% were high school graduates, and $20.2 \%$ were undergraduates. It was found that IBS was significantly more common in women who had low education than the men with the same educational background $(P=0.015)$. Considering their occupations, IBS was found to be significantly more common in women who did not work than in men who did $(P<0.001)$. Considering their marital status, $74.6 \%$ of the patients were married and $25.4 \%$ were single. 
Table 1 Sociodemographic data of the patients

\begin{tabular}{lcc}
\hline Sociodemographic characteristics & $\begin{array}{l}\text { Frequency } \\
(\mathbf{n = 2 4 8 )}\end{array}$ & Percentage (\%) \\
\hline Gender & 139 & 56 \\
$\quad$ Women & 109 & 44 \\
$\quad$ Men & 13 & 5.2 \\
Educational status & 13 & 5.2 \\
$\quad$ Illiterate & 46 \\
$\quad$ Literate & 114 & \\
$\quad$ Primary and secondary school gradu- \\
ate \\
$\quad$ High-school graduate & 58 & 23.4 \\
$\quad$ Undergraduate & 50 & 20.2 \\
Profession & & \\
$\quad$ Housewife/retired & 121 & 48.8 \\
$\quad$ White-collar & 41 & 16.5 \\
$\quad$ Blue-collar & 71 & 28.6 \\
$\quad$ Student & 15 & 6 \\
Marital status & & \\
$\quad$ Married & 185 & 74.6 \\
Single & 63 & 25.4 \\
\hline
\end{tabular}

Table 2 Complaints of the patients at the time of admission

\begin{tabular}{lll}
\hline Complaint & Frequency $(\mathbf{n}=\mathbf{2 4 8})$ & Percentage (\%) \\
\hline Abdominal pain & 166 & 66.9 \\
Abdominal distention & 196 & 79 \\
Intestinal gas & 163 & 65.7 \\
Nausea & 112 & 45.2 \\
Vomiting & 38 & 15.3 \\
Diarrhea & 73 & 29.4 \\
Constipation & 175 & 70.6 \\
Constipation + diarrhea & 58 & 23.4 \\
\hline
\end{tabular}

It was found that the single patients used significantly more herbal products for IBS $(P=0.036)$. The patients were mostly residents of district centers $(46 \%)$. The sociodemographic data of the patients are given in Table 1. The most common complaints among the patients on admission were abdominal distension (79\%), constipation (70.6\%), and abdominal pain (66.9\%) (Table 2). The mean duration of time that the patients had typical IBS symptoms was 5 months (min: 3, max: 43). The number of outpatient clinic visits and the imaging characteristics are given in Table 3. While $87.1 \%$ of the patients did not use the medication that was given to them regularly, $1.6 \%$ used it regularly, and $11.3 \%$ did not receive any medical treatment (Table 4). Of the patients, 102 were receiving herbal therapy (41.1\%), while 146 (58.9\%) were not. Those who received herbal therapy mostly preferred a single
Table 3 Symptom duration, outpatient clinic admission, and imaging characteristics of the patients receiving herbal therapy

\begin{tabular}{ll}
\hline Variable & Median (min-max) \\
\hline Symptoms duration & $5(3-43)$ months \\
Number of visits to a family doctor & $4(0-12)$ \\
Number of visits to a gastroenterology outpatient & $1(0-4)$ \\
clinic & \\
Number of colonoscopies & $1(0-3)$ \\
Number of imagings (ultrasound, CT and MRI) & $2(1-3)$ \\
\hline
\end{tabular}

Table 4 Medical treatment and features related to the herbal therapy use of the patients

\begin{tabular}{lcc}
\hline & $\begin{array}{c}\text { Frequency } \\
(\mathbf{n = 2 4 8 )}\end{array}$ & Percentage (\%) \\
\hline How often patients receive medical treatment & \\
Regularly & 4 & 1.6 \\
Irregularly & 216 & 87.1 \\
$\quad$ Does not receive any & 28 & 11.3 \\
Herbal use & & \\
$\quad$ Using & 102 & 41.1 \\
Not using & 146 & 58.9 \\
\hline
\end{tabular}

herb $(12.5 \%)$ or daily traditional solutions $(12.5 \%)$, such as mint-lemon and linden. Apart from these, they used vegetable oils $(10.1 \%)$ and herb mixtures from herbalists (5\%), respectively. The patients did not have any detailed information about the ingredients of the mixtures that they bought from most of the spice merchants. In addition, traditional treatments generally vary depending on the society but are known by everyone, such as drinking mint and lemon tea for stomach pain and nausea, using fennel tea for abdominal pain, and using probiotic yogurt that contains olive oil and flaxseed for constipation. Other herbal herbs, concoctions (such as tea mixed with mint, fennel, ginger, chamomile, and cinnamon), and oils are herbal products that are usually prepared by the spice merchants. The information and suggestions that the patients received for the use of herbal therapy were mostly from their neighbors, relatives, and friends (57\%). Other sources included the media/internet (34\%) and health professionals (9\%). While the use of herbal herbs and oils was predominant in patients whose content was the media/internet and acquaintances, the herbal treatment content recommended by healthcare professionals consisted of traditional treatments and mixtures $(P=0.012)$. While $23.5 \%$ of the patients found the herbal treatment to be ineffective, $22.5 \%$ stated that they found it to be weakly effective, and $54 \%$ found it to be effective (moderate and very effective). Moreover, 1 patient stated that $\mathrm{s} /$ he experienced life-threatening side 
effects. While $9.8 \%$ of the patients used herbal therapy regularly, $47.06 \%$ did not (Table 5 ). There was no significant relationship between the professions of the patients and the herbal therapy that they used $(P=0.774)$. There was no significant difference in terms of female and male gender in terms of herbal treatment usage $(P=0.573)$. It was found that those who received herbal therapy mostly lived in city centers $(P<0.001)$. Those suffering from diarrhea among the IBS patients preferred to use significantly fewer herbal products $(P=0.007)$. Patients who received medical treatment used herbal therapy less than the others $(P=0.041)$. It was found that the patients who visited the Gastroenterology Outpatient Clinic mostly used herbal therapy, while the patients who visited a family doctor used herbal therapy the least $(P=0.029$, $P<0.001$, respectively) (Table 6). There was no significant relationship between the types of herbal therapies used by the patients and the side effects of these treatments $(P=0.392)$ (Table 7). Patients with constipation preferred to use herbal therapy more than the patients without constipation $(P<0.001)$ (Table 8$)$.

Table 5 Characteristics of herbal treatment

\begin{tabular}{|c|c|c|}
\hline & $\begin{array}{l}\text { Frequency } \\
(n=102)\end{array}$ & Percentage (\%) \\
\hline \multicolumn{3}{|l|}{ Content } \\
\hline Herbal herbs & 31 & 30.4 \\
\hline Oils & 25 & 24.5 \\
\hline Mixtures & 15 & 14.7 \\
\hline Traditional solution & 31 & 30.4 \\
\hline \multicolumn{3}{|c|}{ Recommendation source for herbal use } \\
\hline Media/internet & 35 & 34 \\
\hline Neighbors/relatives/friend & 58 & 57 \\
\hline Health professionals & 9 & 9 \\
\hline \multicolumn{3}{|l|}{ Herbal effect } \\
\hline No effect & 24 & 23.5 \\
\hline Weak & 23 & 22.5 \\
\hline Medium & 26 & 25.5 \\
\hline Good & 22 & 21.6 \\
\hline Very good & 7 & 6.9 \\
\hline \multicolumn{3}{|l|}{ Herbal side effect } \\
\hline No effect & 89 & 87.2 \\
\hline Weak & 8 & 7.8 \\
\hline Medium & 2 & 2 \\
\hline Strong & 2 & 2 \\
\hline Life-threatening & 1 & 1 \\
\hline \multicolumn{3}{|l|}{ Frequency of herbal use } \\
\hline Regular & 10 & 9.8 \\
\hline Often & 44 & 43.14 \\
\hline Occasionally/rarely & 48 & 47.06 \\
\hline
\end{tabular}

Table 6 Comparison of the patients receiving herbal therapy and those not receiving herbal therapy in terms of symptom duration, outpatient clinic admission and imaging

\begin{tabular}{lllr}
\hline Variable & $\begin{array}{l}\text { Using } \\
\text { herbal } \\
\text { therapy } \\
\text { (n=102) } \\
\text { Median } \\
\text { (min-max) }\end{array}$ & $\begin{array}{l}\text { Not using } \\
\text { herbal } \\
\text { therapy } \\
\text { (n=146) } \\
\text { Median } \\
\text { (min-max) }\end{array}$ & P value \\
& $5(3-43)$ & $5(3-43)$ & 0.881 \\
\hline $\begin{array}{l}\text { Symptom duration } \\
\begin{array}{l}\text { Number of visits to a family } \\
\text { doctor }\end{array}\end{array}$ & $3(0-12)$ & $4(0-10)$ & $<0.001$ \\
$\begin{array}{l}\text { Number of visits to a gastroen- } \\
\text { terology outpatient clinic }\end{array}$ & $1(0-4)$ & $0(0-2)$ & 0.029 \\
$\begin{array}{l}\text { Number of colonoscopies } \\
\text { Number of imagings }\end{array}$ & $1(0-3)$ & $1(0-3)$ & 0.811 \\
\hline
\end{tabular}

\section{Discussion}

IBS is a chronic functional disorder of the gastrointestinal tract that is characterized by abdominal pain, abdominal distension, diarrhea, and episodes of constipation, and it has a high prevalence and diverse etiology worldwide $[9,12]$. The current approach in the treatment of this syndrome is to reduce the symptoms rather than eliminate the underlying causes of the disease. Although there are various pharmacological treatment options, due to the limited effectiveness, high cost, and side effects of these treatments, the use of herbal therapy has become more common worldwide. In the current study, patients who received no medical treatment, lived in city centers, and had a relatively low socioeconomic and cultural levels tended to receive herbal therapy. This study was not a community-based study, and the selection of those who wanted to participate in the survey from the patients who had applied to the outpatient clinics was considered as the reason why the gender difference was not evident in both the frequency of IBS and the use of herbal.

The Chinese herbal products that have been used in East Asia for thousands of years are examples of this treatment [13]. Acupuncture, which is a type of

Table 7 Comparison of the types of herbal therapy and their side effects

\begin{tabular}{lcccc}
\hline $\begin{array}{l}\text { Herbal } \\
\text { content }\end{array}$ & $\begin{array}{l}\text { No/weak } \\
\text { herbal effect } \\
\mathbf{n},(\%)\end{array}$ & $\begin{array}{l}\text { Has an } \\
\text { herbal effect } \\
\mathbf{n},(\%)\end{array}$ & Total $\mathbf{n},(\%)$ & $\boldsymbol{P}$ value \\
\hline Herbal herbs & $16,(51.6)$ & $15,(48.4)$ & $31,(100)$ & 0.392 \\
Oils & $14,(56)$ & $11,(44)$ & $25,(100)$ & \\
Mixtures & $6,(40)$ & $9,(60)$ & $15,(100)$ & \\
$\begin{array}{l}\text { Traditional } \\
\text { solution }\end{array}$ & $11,(35.5)$ & $20,(64.5)$ & $31,(100)$ & \\
\hline
\end{tabular}


Table 8 Comparison of the patients receiving herbal therapy and those not receiving herbal therapy in terms of their characteristics

\begin{tabular}{lccc}
\hline Variable & $\begin{array}{l}\text { Using herbal therapy } \\
\mathbf{n},(\%)\end{array}$ & $\begin{array}{l}\text { Not using herbal therapy } \\
\mathbf{n},(\%)\end{array}$ & $\begin{array}{l}\text { Total } \\
\mathbf{n},(\%)\end{array}$ \\
\hline Single & $33,(52.4)$ & $30,(47.6)$ & $63,(100)$ \\
Married & $69,(37.3)$ & $116,(62.7)$ & $185,(100)$ \\
City center & $64,(62.1)$ & $39,(37.9)$ & $103,(100)$ \\
District & $28,(24.6)$ & $86,(75.4)$ & $114,(100)$ \\
Town/village & $10,(32.3)$ & $21,(67.7)$ & $31,(100)$ \\
Women & $55,(39.6)$ & $84,(60.4)$ & $139,(100)$ \\
Men & $47,(43.1)$ & $62,(56.9)$ & $109,(100)$ \\
Employed & $44,(39.3)$ & $68,(60.7)$ & $112,(100)$ \\
Unemployed & $58,(42.6)$ & $78,(57.4)$ & $136,(100)$ \\
Receiving medical treatment & $96,(43.6)$ & $124,(56.4)$ & $220,(100)$ \\
Not receiving medical treatment & $6,(21.4)$ & $22,(78.6)$ & $28,(100)$ \\
Has constipation & $86,(49.1)$ & $89,(50.9)$ & $175,(100)$ \\
Does not have constipation & $16,(21.9)$ & $57,(78.1)$ & $73,(100)$
\end{tabular}

traditional medicine that has been mentioned frequently in the media, can also be used with herbal therapies, and in a study by Yan et al., the administration of herbal therapy together with acupuncture was found to be safe and effective [14]. As it is around the world, some of the patients herein who participated in the study tended to use herbs and traditional methods. Although the herbal therapies used were partially effective with a single use, it has been reported that the combinations created from these products can also be used, and this may be more beneficial [9]. It is also believed that many factors, such as the regular use of these products and the regular maintenance of medical treatment by the patient, affect the benefits obtained from herbal products. It was believed herein that regular treatment and follow-up can have a positive effect on IBS and herbal treatment, as in every disease. These products, which are also popular with IBS patients, have gained vast attention in the written, visual, and verbal media. Although most of the participants in the current study obtained their herbal product recommendations from their neighbors, relatives, and friends, the influence of the media in the selection of herbal products was also quite high. The patients obtained advisory information for these herbal therapies from the media rather than from health professionals. The effect/side effect profile of herbal therapies is not clear, as different herbal therapies may show different effects on patients, and these unpredictable effects have a wide spectrum, from acute renal failure to toxic hepatitis. It is obvious that the information given about these herbal products covered in the media may not be objective, non-commercial, or completely correct [15]. Unfortunately, because of commercial concerns or hearsay information about these products, for which safety and efficacy criteria are not clear, patients may be misled, and these products may cause various side effects or less beneficial effects than expected. A study by Munyaradzi et al. evaluated the effects of advertisements for herbal therapies on African societies and found that the headlines used in media-based advertisements and interesting statements about the product, even if not scientific information, affected the decisions of the patients [16]. It is thought that the herbal products used by IBS patients, which may be beneficial/harmful or have no effect in various situations, may deviate from their purpose due to the biased/ unbiased promotion of the media and bilateral relations in daily life. The fact that the majority of patients who participated in the current study did not receive herbal therapy may be a result of these concerns.

Madisch A et al. reported in their study that $54 \%$ of primary care physicians were satisfied with the success of spasmolytic treatment, and $75 \%$ were satisfied with phyto-therapeutic agents and probiotics [17].

\section{Conclusion}

For IBS patients to use herbal products correctly and appropriately, they should be provided unbiased information about these herbal products. Relatives, neighbors, etc. In this regard, the addition of training curricula related to herbal treatment for professional healthcare workers will further raise awareness and it will increase the conscious use of herbal medicine in the treatment of IBS. 


\section{Appendix}

The questionnaire about evaluation of knowledge and attıtude of persons with gastroenterological complaints:

Dear Participant,

This questionnaire form has been developed to collect data on "Assessment of Knowledge and Attitude Level of Persons with Gastroenterological Complaints". Please put an (X) in front of the option that suits you. Write your answer in the blank for questions that are not given options. Thank you for your contribution.

\section{DEFINITIONAL FEATURES}

1. Birthday (as year):

2. Place of birth:

Centrum $(\ldots \ldots) \quad$ district $(\ldots \ldots) \quad$ town-village $(\ldots$.

3. Gender: Female (...) Male (...)

4. Educational status:

Illiterate (...) Literate (....) primary school graduate (....)

Secondary school graduate(...) High school graduate(......)

Collage/university graduate (....)

5. Job: $(\ldots \ldots \ldots \ldots)$

6. Where do you live in?

Centrum $(\ldots ..) \quad \operatorname{district}(\ldots$.$) \quad town-village (. . .$.

7. Marital status: $\quad$ Single (.....) Married (.....)

8. Your wife/husband's job? $\quad(\ldots \ldots \ldots \ldots \ldots \ldots)$

9. Do you have daughter or son? $\quad$ Yes(....) No(...)

10. How many people are there in the house including you? $($.

\section{STATUS OF KNOWLEDGE AND ATTITUDE}

11. What are your complaints about health?

Stomachache (.....) swelling (....) excessive gas expulsion (...) nausea (..)

Constipation (...) diarrhea (...)

12. Age of onset of complaints (...)

13. Did you apply to hospital about your complaints? 
14. How many times did you apply to hospital about your complaints? ..)

15. Which treatment options did you use about your complaints? .)

16. Did you take help about these complaints from anybody except your doctor? $(\ldots \ldots \ldots \ldots \ldots \ldots)$

17. Did you use herbal products about these complaints? Yes(...) No(...) If your answer is yes, what were they?

18. Where did you learn these herbal products?

Television(...) internet (....) radio (....) doctor(.....) non-doctor health employee (...) friends (....) neighboor(....) herbalist $(\ldots \ldots)$ apotheke $(\ldots \ldots)$ other $(\ldots \ldots .$.

19. Have you ever asked your doctor for an examination / medication from the media or the environment? Yes (....) no $(\ldots \ldots \ldots)$

20. Did you continue your medical treatment receipted by your doctor as well as herbal products? $\quad$ Yes $(. . .$.$) \quad no(.....)$

21. Do you think you benefit from these products?

$1=\mathrm{I}$ didn't see any benefit. $2=\mathrm{I}$ had little benefit. $3=\mathrm{I}$ had medium benefit.

4= I saw good benefit. 5= I saw a lot of benefit.

22. Do you think you were harmed by these products?
$1=\mathrm{I}$ had no harm
$2=\mathrm{I}$ had a little harm
3= I had medium harm.
4= I had some harm
$5=\mathrm{I}$ had a lot of harm.

23. What kind of harms did you have? ( .)

24. Did you apply to hospital about these harms? (

...)

25. Is anyone around you damaged by these products? .).

\section{Acknowledgements}

Thank you to our assistant and specialist doctor friends who have supported our work in the Internal Medicine Clinic.

\section{Authors' contributions}

EG, NYC, SB, SK and OE: investigation, project administration, software, visualization, writing-review and editing, methodology. All authors read and approved the final manuscript.

\section{Funding}

The author(s) received no financial support for the research, authorship, and/ or publication of this article.

\section{Availability of data and materials}

The datasets used and/or analyzed during the current study are available from the corresponding author on reasonable request.

\section{Declarations}

Ethics approval and consent to participate

Ankara City Hospital No.1 Clinical Research Ethics Committee approval was received for this study at 25.11.2020, Approval number: E1-20-1312. Informed consent was obtained from all patients participating in the study.

\section{Consent for publication}

Not applicable. 


\section{Competing interests}

The authors declare no competing interests.

\section{Helsinki declaration}

The authors declared that this study is in accordance with the Helsinki Declaration.

\section{Author details}

'Department of Internal Medicine, Ankara City Hospital, Ankara 06100, Turkey. ${ }^{2}$ Department of Internal Medicine, Yildırım Beyazıt University School of Medicine, Ankara, Turkey. ${ }^{3}$ Department of General Surgery, Ankara City Hospital, Ankara, Turkey. ${ }^{4}$ Department of Gastroenterology, Yıldırım Beyazıt University School of Medicine, Ankara, Turkey.

Received: 8 March 2021 Accepted: 21 January 2022

Published online: 04 February 2022

\section{References}

1. Hungin AP, Whorwell PJ, Tack J, et al. The prevalence, patterns and impact of irritable bowel syndrome: an international survey of 40.000 subjects. Aliment Pharmacol Ther. 2003;17:643-50.

2. Lovell RM, Ford AC. Global prevalence of and risk factors for irritable bowel syndrome: a meta-analysis. Clin Gastroenterol Hepatol. 2012;10:712-21.

3. Brandt LJ, Chey WD, et al. An evidence-based position statement on the management of irritable bowel syndrome: American Collage of Gastroenterology task force on irritable bowel syndrome. Am J Gastroenterol. 2009;104(Suppl 1):S1-35.

4. Houghton LA, Heitkemper M, Crowell MD, et al. Age, gender, and women's health and the patient. Gastroenterology. 2016;150:1332-43.

5. Howell S, Talley NJ, Quine S, Poulton R. The irritable bowel syndrome has origins in the childhood socioeconomic environment. Am J Gastroenterol. 2004;99(8):1572-8. https://doi.org/10.1111/j.1572-0241. 2004.40188.x (PMID: 15307879).

6. El-Serag HB, Olden K, Bjorkman D. Health-related quality of life among persons with irritable bowel syndrome: a systematic review. Aliment Pharmacol Ther. 2002;16:1171-85.

7. Lacy BE, Chey WD, Lembo AJ. New and emerging treatment options for irritable bowel syndrome. Gastroenterol Hepatol (N Y). 2015;11(4 Suppl 2):1-19.

8. Lacy BE, Mearin F, Chang L, et al. Bowel disorders. Gastroenterology. 2016:150:1393-407.

9. Bahrami HR, Hamedi S, Salari R. Herbal medicines for the management of irritable bowel syndrome: a systematic review. Electron Phys. 2016;8(8):2719-25.

10. Spanier JA, Howden CW, Jones MP. A systematic review of alternative therapies in the irritable bowel syndrome. Arch Intern Med. 2003; 163(3):265-74.

11. Ekor $M$. The growing use of herbal medicines: issues relating to adverse reactions and challenges in monitoring safety. Front Pharmacol. 2014;10(4):177. https://doi.org/10.3389/fphar.2013.00177.

12. Rahimi R, Abdollahi M. Herbal medicines for the management of irritable bowel syndrome: a comprehensive review. World J Gastroenterol. 2012;18(7):589-600. https://doi.org/10.3748/wjg.v18.i7.589.

13. Bi Z, Zheng Y, Yuan J, Bian Z. The efficacy and potential mechanisms of Chinese herbal medicine on irritable bowel syndrome. Curr Pharm Des. 2017;23(34):5163-72. https://doi.org/10.2174/13816128236661708221 01606.

14 Yan J, Miao ZW, Lu J, et al. Acupuncture plus Chinese herbal medicine for irritable bowel syndrome with diarrhea: a systematic review and metaanalysis. Evid Based Complement Alternat Med. 2019;2019:7680963. https://doi.org/10.1155/2019/7680963.

15 Peacock M, Badea M, Bruno F, et al. Herbal supplements in the print media: communicating benefits and risks. BMC Complement Altern Med. 2019;19(1):196. https://doi.org/10.1186/s12906-019-2602-9.

16. Munyaradzi M. Ethical quandaries in spiritual healing and herbal medicine: a critical analysis of the morality of traditional medicine advertising in southern African urban societies. Pan Afr Med J. 2011;10:6. https://doi. org/10.4314/pamj.v10i0.72212.

17. Madisch A, Labenz C, Hollenz M, Gross M, Labenz J. Therapiemanagement des reizdarmsyndroms in der hausarztpraxis : probiotika und phytotherapeutika kommen häufig erfolgreich zum einsatz [therapeutic management of irritable bowel syndrome in the family doctor's practice - probiotics and phytotherapeutics are often used successfully]. MMW Fortschr Med. 2020;162(Suppl 5):7-13.

\section{Publisher's Note}

Springer Nature remains neutral with regard to jurisdictional claims in published maps and institutional affiliations.
Ready to submit your research? Choose BMC and benefit from:

- fast, convenient online submission

- thorough peer review by experienced researchers in your field

- rapid publication on acceptance

- support for research data, including large and complex data types

- gold Open Access which fosters wider collaboration and increased citations

- maximum visibility for your research: over 100M website views per year

At BMC, research is always in progress.

Learn more biomedcentral.com/submissions 